\title{
Basic life support and automated external defibrillator skills among ambulance personnel: a manikin study performed in a rural low-volume ambulance setting
}

\author{
Anne Møller Nielsen ${ }^{1 *}$, Dan Lou Isbye ${ }^{1}$, Freddy Knudsen Lippert ${ }^{2}$ and Lars Simon Rasmussen ${ }^{1}$
}

\begin{abstract}
Background: Ambulance personnel play an essential role in the 'Chain of Survival'. The prognosis after out-ofhospital cardiac arrest was dismal on a rural Danish island and in this study we assessed the cardiopulmonary resuscitation performance of ambulance personnel on that island.

Methods: The Basic Life Support (BLS) and Automated External Defibrillator (AED) skills of the ambulance personnel were tested in a simulated cardiac arrest. Points were given according to a scoring sheet. One sample $t$ test was used to analyze the deviation from optimal care according to the 2005 guidelines. After each assessment, individual feedback was given.

Results: On 3 consecutive days, we assessed the individual EMS teams responding to OHCA on the island. Overall, $70 \%$ of the maximal points were achieved. The hands-off ratio was 40\%. Correct compression/ventilation ratio (30:2) was used by $80 \%$. A mean compression depth of $40-50 \mathrm{~mm}$ was achieved by $55 \%$ and the mean compression depth was $42 \mathrm{~mm}$ (SD $7 \mathrm{~mm}$ ). The mean compression rate was 123 per min (SD 15/min). The mean tidal volume was $746 \mathrm{ml}$ (SD $221 \mathrm{ml})$. Only the mean tidal volume deviated significantly from the recommended $(p=0.01)$. During the rhythm analysis, 65\% did not perform any visual or verbal safety check.

Conclusion: The EMS providers achieved $70 \%$ of the maximal points. Tidal volumes were larger than recommended when mask ventilation was applied. Chest compression depth was optimally performed by $55 \%$ of the staff. Defibrillation safety checks were not performed in $65 \%$ of EMS providers.
\end{abstract}

Keywords: Emergency Medical Services, Training, Basic Life Support, Manikin

\section{Background}

Survival after out-of-hospital cardiac arrest (OHCA) is generally below $10 \%$, a figure that has remained essentially unchanged over the past three decades despite efforts to improve survival [1]. The 'Chain of Survival' comprises early recognition of the cardiac arrest, early cardiopulmonary resuscitation (CPR), early defibrillation and post-resuscitation care, which are the actions needed for successful resuscitation[2]. The quality of CPR appears to impact the survival [3-5], but unfortunately

\footnotetext{
* Correspondence: mnielsen.anne@gmail.com

'Department of Anaesthesia, Centre of Head and Orthopaedics, Copenhagen University Hospital, Rigshospitalet, Blegdamsvej 9, Copenhagen 2100, Denmark

Full list of author information is available at the end of the article
}

the CPR quality has been shown to be poor and not consistent with international guidelines for resuscitation, even when performed by health care professionals [6-8].

On the rural Danish island of Bornholm no one survived an OHCA in 2001-2003 [9]. Therefore a multifaceted approach was launched in September 2008 with the purpose to increase the survival after OHCA by improving the quality of each link in the 'Chain of Survival'. The Emergency Medical Service (EMS) providers are an important part of this by providing CPR and defibrillation, especially in rural areas with long transportation times. Little is known about the resuscitation skills in low-volume EMS as most research performed in the area is conducted in larger cities. The aim of this study was

\section{Biomed Central}

(c) 2012 Møller Nielsen et al.; licensee BioMed Central Ltd. This is an Open Access article distributed under the terms of the Creative Commons Attribution License (http://creativecommons.org/licenses/by/2.0), which permits unrestricted use, distribution, and reproduction in any medium, provided the original work is properly cited. 
to determine the Basic Life Support (BLS) and Automated External Defibrillator (AED) skills in the EMS providers on the island. Thereby we would be able to intervene where needed and hopefully also improve the quality of care.

\section{Methods \\ Setting}

Bornholm is an island of $588 \mathrm{~km}^{2}$ with a population of 42.000.The number of OHCA is approximately 50 cases per year.

\section{EMS system}

At the time of the investigation (May 2009) the EMS response to presumed OHCA was an ambulance unit manned with two BLS providers trained in the use of a defibrillator in AED-mode. The unit was dispatched from two different locations simultaneously with a BLS provider operated first responder unit. There was no paramedic-, nurse- or physician-manned ambulances on the island.

There were 22 EMS providers on the island educated as 'level 2' providers and 13 educated as 'level 1' providers. All are trained in BLS and AED use, but the level 2 providers have received additional training in ECG interpretation and completed the international certified Pre-Hospital Trauma Life Support course [10]. The EMS providers work together in pairs on a 24-hour shift every third day. During each shift one EMS provider is assigned the leader and the other an assistant. The assistant may be a 'level 1' EMS provider, but the leader has to be a 'level 2' provider.

OHCA was treated in accordance with the European Resuscitation Council (ERC) Guidelines for Resuscitation 2005. The treatment of unwitnessed OHCA was 2 min of CPR prior to rhythm analysis [11].

\section{BLS/AED assessment}

On the 25th, 26th and 27th of May 2009 we assessed the BLS and AED skills of the individual EMS teams responding to $\mathrm{OHCA}$ on the island.

The teams were called one by one to the main station during their shift and were told that they had to participate in a simulated cardiac arrest situation. They were to bring all their usual equipment and the scenario was: "An adult citizen has called the dispatch centre and reported that he is unwell and alone in his house. Upon arrival you find the citizen lying on the floor, apparently without signs of life. There is no one else around."

Ideally the EMS team should recognise cardiac arrest, start and continue CPR for 2 min while attaching the defibrillator (Physio-Control LifePak 15) in AED-mode. A rhythm check should be performed while ensuring nobody touched the victim. In the scenario the rhythm was shockable and a safety check should be performed before pushing the shock button. Then CPR should be performed for another $2 \mathrm{~min}$ and the test was stopped just after the second rhythm check.

All 'level 2' providers were tested as the leader. The assistant was either a 'level 1' or a 'level 2' provider, according to the on-duty schedule the specific day. The roles were predefined; the assistant provided chest compressions and maybe ventilations for the first $2 \mathrm{~min}$ and after that, only chest compressions.

Skills were assessed on a resuscitation manikin (ResusciAnne HLR-D, Laerdal Medical, Stavanger, Norway) and in accordance with the ERC Guidelines for Resuscitation 2005 [12]. A laptop running Laerdal PC SkillReporting System version 2.0 (Laerdal Medical, Stavanger, Norway) was connected to the manikin and registered the data on hand placement, compression depth, total number of compressions and ventilations, ventilation volume, total hands-off time, delay until first compression or ventilation and time until first shock.

An ERC-certified BLS/AED instructor, ALS provider, and medical doctor obtained ordinal data and registered these on a form during assessment. The following variables were collected: checking for responsiveness by talking and shaking, opening the airway, checking for respiration and pulse, starting BLS, performing safety checks, removing oxygen during shock and compression/ ventilation ratio. Before the assessment it was decided that; ideally BLS should be initiated within $15 \mathrm{sec}$, delay was the time until first compression or ventilation, hand position was incorrect if one compression was in the wrong position, correct compression:ventilation ratio was $30 \pm 2: 2$, and participants who attempted a ratio of 30:2 were registered as such even if ventilations were unsuccessful. There were $2 \times 2$ min for compressions and ventilations, thus an optimal 300 compressions and 20 ventilations could be performed within this timeframe. The hands-off time was defined as the time without compressions being performed and the hands-off ratio was the hand-off time divided by the scenario length.

A scoring sheet was developed from the Cardiff test [13] and the scores allocated to each of the 22 categories can be seen in Additional file 1 . The total score ranged from 19-70. The percentage of the maximal achievable was calculated by dividing the average score (minus 19) with the maximal score (70-19).

\section{Statistics}

Data are reported as mean with standard deviation $( \pm \mathrm{SD})$. Descriptive statistics were used to characterize the sample and each of the questions. We decided that the mean tidal volume should not exceed $600 \mathrm{ml}$, the mean compression depth should be more than $40 \mathrm{~mm}$, the mean total number of ventilations should be below 20 and the mean compression rate should not exceed 
$120 /$ min. To test if the performance of the EMS providers deviated significantly from these values a one sample $t$ test was performed. P-values below 0.05 were considered statistically significant.

\section{Feedback}

After each assessment, individual feedback was given to the EMS providers. Good performance was pointed out and the skills that needed improvement were identified and explained. This was done by the medical doctor who had also performed the assessment.

\section{Results}

We tested 20 (91\%) of the 22 level 2 EMS providers on Bornholm as the leader; one was on holiday and one was absent due to illness. Seventeen (85\%) were male. Thirteen level 1 providers participated as assistants. The obtained skills can be seen in Additional file 1. The mean total score was $55( \pm 4)$ equal to $70 \%$ of the maximal achievable score according to the Cardiff test.

The mean delay from the start of the scenario to the first compression or ventilation was $35( \pm 9) \mathrm{sec}$ and the mean time until the first shock was delivered was $162( \pm 52) \mathrm{sec}$.

The mean hands-off time was $122( \pm 25)$ sec and the hands-of ratio was $40 \%$. The mean scenario length was 303 $( \pm 54)$ sec.

Data on recognition of cardiac arrest can be seen in Figure 1 . Of the $75 \%$ who checked pulse, all but one (radial artery) used the carotid artery.

\section{Algorithms of resuscitation}

After recognition of cardiac arrest all started BLS and 50\% continued for the recommended $2 \mathrm{~min}$. Eighty percent used the correct compression:ventilation ratio (30:2), one was using the ratio from Guidelines 2000 (15:2) and 3 were only doing compressions. The person giving chest compressions was changed every 2 min by 35\%. All switched on the AED, but after defibrillation, $15 \%$ checked the rhythm, pulse or other signs of life instead of continuing CPR immediately.

\section{Compressions}

The hand-placement was correct for $45 \%$ of the EMS providers. The mean compression depth was $42( \pm 7)$ $\mathrm{mm}$ (Figure 2) and not significantly different from the minimum value of $40 \mathrm{~mm}(\mathrm{p}=0.26)$. Likewise, the mean compression rate of $123( \pm 15) /$ min (figure 2) was not significantly different from our defined maximum compression rate of $120(\mathrm{p}=0.37)$, but 10 of 20 participants had rates higher than the maximally allowed.

The mean number of compressions given in the $2 \times 2$ min of BLS was $345( \pm 95)$.

\section{Ventilations}

The mean tidal volume was $746( \pm 221)$ ml (Figure 3) and significantly higher than $600 \mathrm{ml}(\mathrm{p}=0.01)$. Seventeen of 20 participants had ventilation volumes higher than $600 \mathrm{ml}$. A mean of $20( \pm 9)$ ventilations (figure 3) was given in the $2 \times 2$ min of BLS, which was not significantly different from $20(\mathrm{p}=0.8)$.

\section{Defibrillation}

Data on safety checks when operating the AED can be seen in Figure 4. All removed the oxygen mask, but $90 \%$ removed it less than 1 meter.

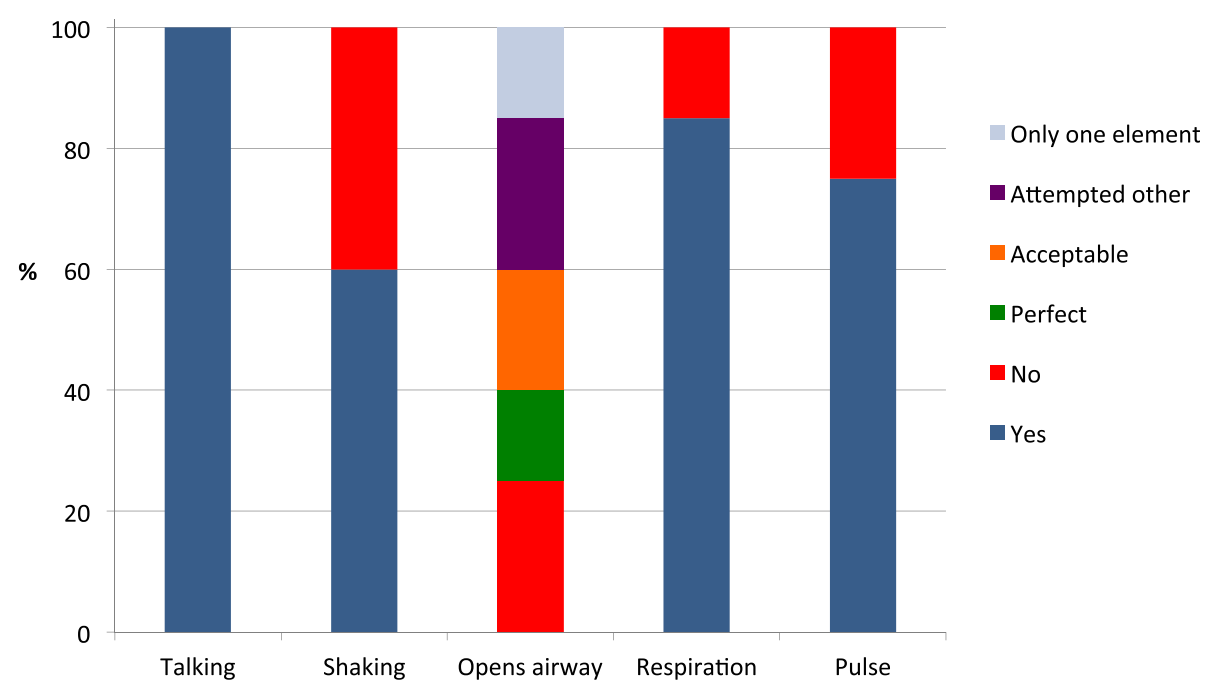

Figure 1 Recognition of cardiac arrest by ambulance personnel $(\mathrm{N}=20)$. 

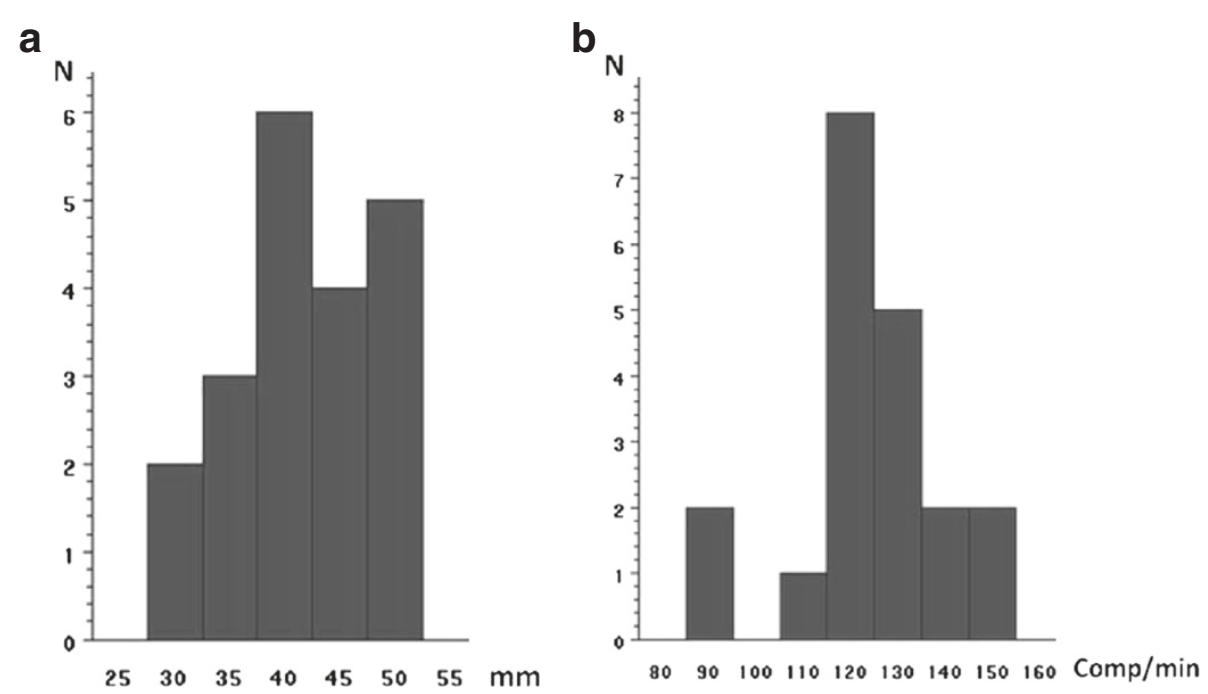

Figure 2 Compression depth and rate. Part a: The mean compression depth $(\mathrm{mm})$ performed by the ambulance personnel $(\mathrm{N}=20)$. The recommended compression depth in guidelines 2005 for resuscitation was $40-50 \mathrm{~mm}$ and 55\% achieved this. Part b: The mean compression rate (compressions/min) performed by the ambulance personnel $(\mathrm{N}=20)$. The optimal compression rate according to guidelines 2005 for resuscitation was $100 / \mathrm{min}$.

\section{Discussion}

In this assessment of the BLS and AED skills in the cohort of EMS providers in a local low-volume Scandinavian ambulance setting, $70 \%$ of the maximal achievable score according to the Cardiff test was reached. There is, however, room for improvements. Compressions were given at a higher rate than recommended in the guidelines but compression depth was adequate in a majority of cases. Ventilation was successful but tidal volume was significantly higher than the maximum recommended value. All managed to deliver a defibrillation shock, but the safety checks in relation to AED managing were not satisfactory in all subjects.

The strengths of our study include that the study population comprised $91 \%$ of the entire cohort of EMS providers 'level 2 ' in the community and thus gives a realistic assessment of the available resuscitation skills. The ordinal data was registered by one doctor only, thus avoiding inter observer variability. Given that the study was performed with a manikin and not actual cardiac arrest victims, one could argue that this dummy setting does not extrapolates to real life. On the other hand, this design enabled us to study variables, which has not been studied in real life settings, like the recognition of cardiac arrest and safety checks related to the AED deployment. Also our measurements of variables such as ventilation volume and compression depth might be more consistent. A limitation is that the EMS providers knew that they were to participate in a research project regarding resuscitation skills. Another limitation is that it would have been beneficial to create a specific course where the identified skills needing improvement could have been trained systematically and afterwards re-assessed. Unfortunately, for logistics and economic reasons this was not possible. One could argue that our emphasis on safety checks is rather large, since the EMS providers often are performing resuscitation alone in the vehicle during transport. But in the patients home they are working together and likely with relatives present.

Throughout the ERC guidelines for resuscitation 2005 and $2010[14,15]$ there is increased emphasis on minimally interrupted high-quality chest compressions and both human [16] and animal $[17,18]$ studies have shown that even short interruptions in chest compressions are associated with worse outcome.

Previously the quality of real life EMS CPR has been found to be poor with no compressions being given $48 \%$ of the time $(38 \%$ when subtracting time for defibrillation) [6] and 57\% of the time, respectively [8]. More recent studies have shown improvements in the hands-off ratios following the Guidelines 2005 for resuscitation, from $23 \%$ to $14 \%$ [19], and $49 \%$ to $34 \%$ [20], respectively.

The hands-off ratio in our study was $40 \%$. Some time without chest compressions is unavoidable (e.g. for recognition of cardiac arrest and defibrillation) but the above mentioned clinical studies do not take this into account. Therefore, the hands-off ratio in our study is high, especially since it was a manikin study with no interruptions due to placement of i.v. lines or loading of the patient into the EMS vehicle. In a recent Danish study 

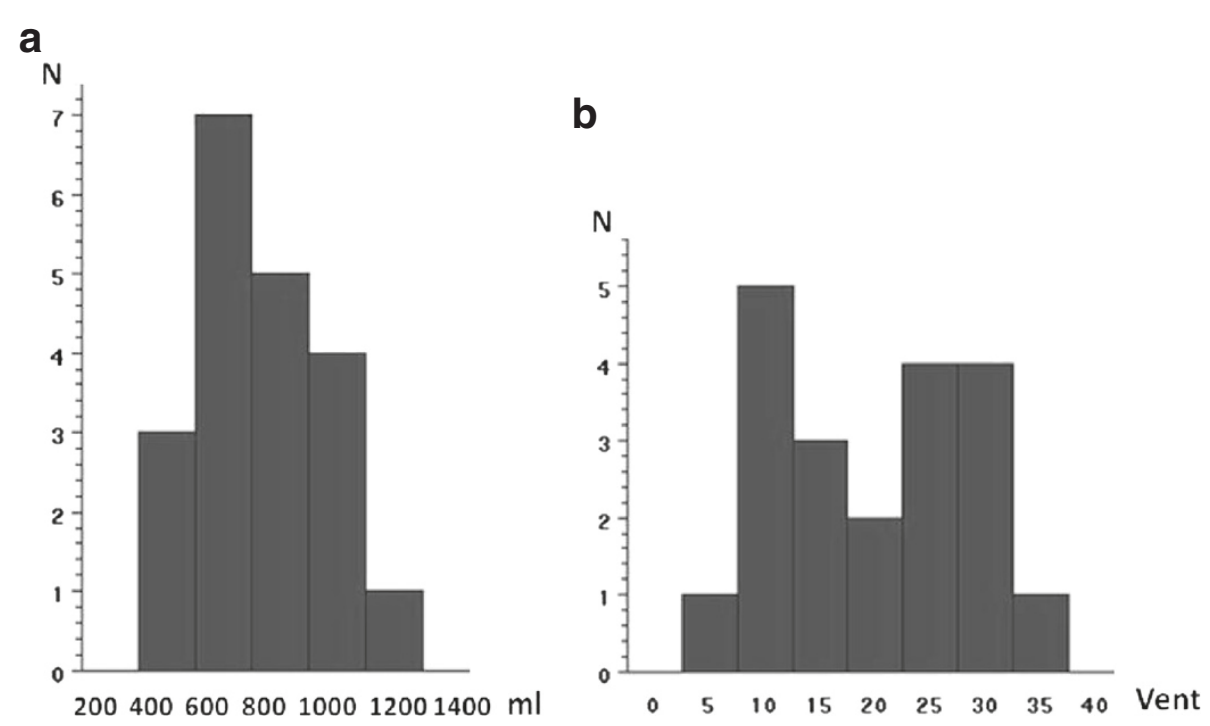

Figure 3 Tidal volume and number of ventilations. Part a: The mean tidal volume $(\mathrm{ml})$ performed by the ambulance personnel $(\mathrm{N}=20)$. The recommended tidal volume according to guidelines 2005 for resuscitation was 500-600 ml and 10\% achieved this. Part b: The total number of ventilations performed by the ambulance personnel $(\mathrm{N}=20)$. In our scenario the optimal number of ventilations was 20.

exactly the loading of the patient was found to be a major contributor to hands-off time [21]. Thus, one of the very important aspects of the guidelines (minimizing the hands-off time) was not performed well by the EMS providers.

Another important parameter discussed in the guidelines is the quality of chest compressions. In our study $55 \%$ achieved a compression depth of $40-50 \mathrm{~mm}$, which was the recommended depth in guidelines 2005 [12]. The average compression depth was not significantly too shallow, but still $30 \%$ provided compressions that were too shallow. One study has shown that shallow compressions were associated with defibrillation failure [16] and other studies have shown that increasing compression depth was correlated with increasing short-term survival [22,23]. Clinical studies have documented prevalence of too shallow compressions $[6,7,24]$ whereas EMS manikin studies have reported that up to $50 \%$ of the compressions were too deep $[25,26]$. Thus our study is not concurrent with other manikin studies and points out a skill that needs improvement. The mean compression rate was 123 $( \pm 15) / \mathrm{min}$, which was too high but in accordance with other studies $[19,23,24]$. Only $35 \%$ changed the person

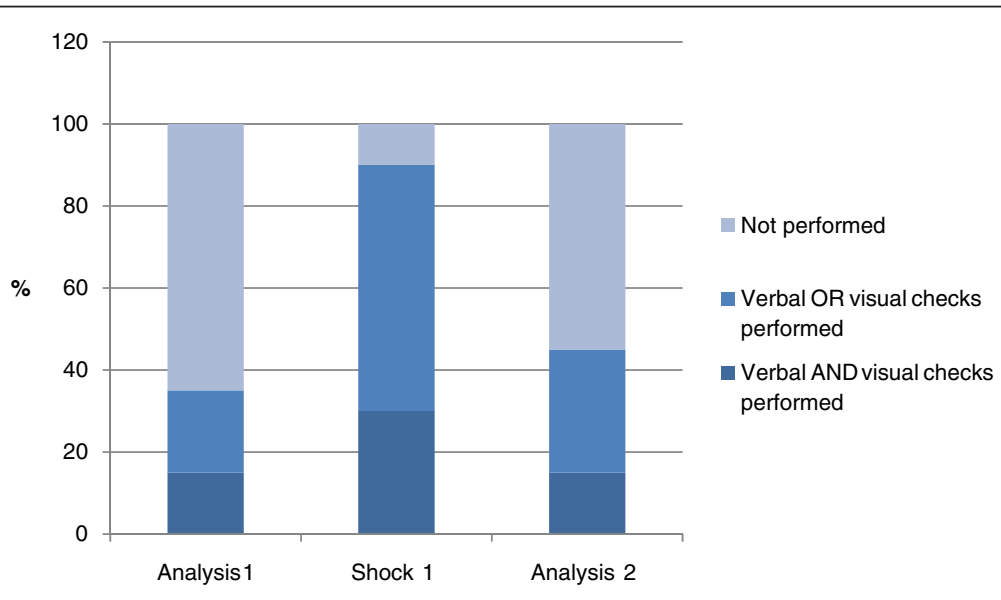

Figure 4 Safety checks. Safety checks performed by the ambulance personnel $(\mathrm{N}=20)$ during Automated External Defibrillator analysis and before pushing the 'shock' button. 
providing chest compressions every 2 minutes, which is emphasized in the guidelines and only $45 \%$ had a correct hand position.

In our study the mean tidal volume was $745( \pm 221)$ $\mathrm{ml}$, and significantly exceeding the recommended maximum of $600 \mathrm{ml}$. Only 10\% reached the recommended ventilation volume $(500-600 \mathrm{ml})$ and $75 \%$ hyperventilated the manikin. In porcine models hyperventilation has resulted in increased intrathoracic pressure, decreased coronary perfusion pressure and survival rate [27].

A fundamental rule in all first aid is 'safety first' and therefore it is surprising that more than half of the EMS providers did not perform any hands-off checks during rhythm analysis and only 30\% performed both a visual and a verbal hands-off safety check before pushing the shock button. During training, safety checks in relation to the AED should be reinforced.

With regard to recognition of cardiac arrest it is recommended in the guidelines that looking for signs of life should take no more than $10 \mathrm{sec}$ [14]. In our study the delay from start of the scenario to the first compression or ventilation was $35( \pm 9)$ sec. Studies with trained laypersons have reported similar excessive times $(29-40 \mathrm{sec})$ for recognition of cardiac arrest [28-30]. When recognizing cardiac arrest 25\% did not make any attempt at opening the airway which is higher than the reported $11 \%$ in a manikin study with trained emergency healthcare professionals [25]. After recognizing the unwitnessed cardiac arrest, only half performed BLS for $2 \mathrm{~min}$, which was the current guideline. With regard to correct compression/ventilation ratio $(30: 2)$ is it surprising that only $80 \%$ were able to recall this, $3 \frac{1}{2}$ years after the guidelines changed. An explanation could be that the island's ambulance company (Falck a/s) had a delay of at least $1 \frac{1}{2}$ year in implementing the guidelines 2005 [31]. All the issues mentioned in this paragraph are simple cognitive skills and one could speculate if enough attention has been paid to maintenance of EMS providers' resuscitation skills.

When evaluating the BLS/AED skills in the cohort of EMS providers in a rural low-volume Scandinavian community, $70 \%$ of the maximal achievable score according to the Cardiff test was reached. These are the health care professionals who are on duty with the responsibility of taking care of a real cardiac arrest and one could expect a better performance, especially given the inoffensive training scenario. The study took place on a rural island with only approximately 50 cardiac arrests annually, calling for frequent training in BLS/ AED. Our findings suggest that this training most likely has been too moderate and in that way our results might extrapolate to the rest of the country as the island's EMS operator covers approximately $85 \%$ of the population in Denmark. In addition, our findings might be generalizable to other similar rural settings in Scandinavia.

Identifying suboptimal performance demands action. The EMS providers should be trained at regular intervals in realistic settings and with qualified instructors. Personnel employed in rural areas might benefit from a rotation system with shifts in more busy areas. This study points out specific difficulties to which training should be targeted. For instance, the recognition of cardiac arrest probably deserves more attention in resuscitation training, including stressing the importance of checking the airways. The manikin was ventilated successfully, but with high tidal volumes. In addition, the tidal volumes were given with very large variability, indicating that this is another skill that should be trained carefully.

\section{Conclusion}

In conclusion, the EMS providers in a rural low-volume Scandinavian setting achieved $70 \%$ of the maximal points when their BLS and AED skills were tested in a simulated cardiac arrest. In order to improve the quality of care, future training should be targeted to recognition of cardiac arrest, minimizing the hands-off time, and providing ventilation with adequate tidal volumes. Defibrillation safety checks should be reinforced.

\section{Additional file}

Additional file 1: Assessment of resuscitation skills in ambulance personnel. Assessment of resuscitation skills in ambulance personnel with points allocated to the different resuscitation skills.

\section{Abbreviations}

AED: Automated External Defibrillator; BLS: Basic Life Support (BLS); CPR: Cardiopulmonary Resuscitation; EMS: Emergency Medical Service; ERC: European Resuscitation Council; OHCA: Out-of-hospital cardiac arrest; SD: Standard deviation.

\section{Competing interests}

The authors declare that they have no competing interests.

\section{Acknowledgments}

The first author has received an unrestricted research grant from the TrygFonden foundation, Denmark. Laerdal Medical has supplied the resuscitation manikin and the Laerdal PC SkillReporting System. Neither TrygFonden nor Laerdal Medical has taken any part in designing the study; in collecting, analysing or interpretation of the data; in the writing or approving of the manuscript or in the decision to submit the manuscript for publication.

\section{Author details}

${ }^{1}$ Department of Anaesthesia, Centre of Head and Orthopaedics, Copenhagen University Hospital, Rigshospitalet, Blegdamsvej 9, Copenhagen 2100, Denmark. ${ }^{2}$ Emergency Medicine and Emergency Medical Services, Head Office, The Capital Region of Denmark, Kongens Vænge 2, Hillerød 3400, Denmark. 


\section{Authors' contributions}

All authors made contributions to conception and design and interpretation of data. AMN acquired the data, drafted the manuscript and AMN and LSR performed the statistical analysis. LSR, DLI and FKL have revised the manuscript critically for important intellectual content. All authors read and approved the final manuscript.

Received: 4 January 2012 Accepted: 8 May 2012

Published: 8 May 2012

\section{References}

1. Sasson C, Rogers MA, Dahl J, Kellermann AL: Predictors of survival from out-of-hospital cardiac arrest: a systematic review and meta-analysis. Circ Cardiovasc Qual Outcomes 2010, 3:63-81.

2. Nolan J, Soar J, Eikeland H: The chain of survival. Resuscitation 2006, 71:270-271.

3. Gallagher EJ, Lombardi G, Gennis P: Effectiveness of bystander cardiopulmonary resuscitation and survival following out-of-hospital cardiac arrest. JAMA 1995, 274:1922-1925.

4. Christenson J, Andrusiek D, Everson-Stewart S, Kudenchuk P, Hostler D, Powell J, Callaway CW, Bishop D, Vaillancourt C, Davis D, Aufderheide TP, Idris A, Stouffer JA, Stiell I, Berg R: Chest compression fraction determines survival in patients with out-of-hospital ventricular fibrillation. Circulation 2009, 120:1241-1247.

5. Wik L, Steen PA, Bircher NG: Quality of bystander cardiopulmonary resuscitation influences outcome after prehospital cardiac arrest. Resuscitation 1994, 28:195-203.

6. Wik L, Kramer-Johansen J, Myklebust H, Sorebo H, Svensson L, Fellows B, Steen PA: Quality of cardiopulmonary resuscitation during out-of-hospital cardiac arrest. JAMA 2005, 293:299-304.

7. Abella BS, Alvarado JP, Myklebust H, Edelson DP, Barry A, O'Hearn N, Vanden Hoek TL, Becker LB: Quality of cardiopulmonary resuscitation during in-hospital cardiac arrest. JAMA 2005, 293:305-310.

8. Valenzuela TD, Kern KB, Clark LL, Berg RA, Berg MD, Berg DD, Hilwig RW, Otto CW, Newburn D, Ewy GA: Interruptions of chest compressions during emergency medical systems resuscitation. Circulation 2005, 112:1259-1265.

9. Danish Cardiac Arrest Registry 2005. [http://www.regionh.dk/ kliniskedatabaser/menu/]

10. National Association of Emergency Medical Technicians. Pre-Hospital Trauma Life Support. [http://www.naemt.org/education/PHTLS/phtls.aspx]

11. Nolan J, Deakin CD, Soar J, Böttiger BW, Smith G: European Resuscitation Council guidelines for resuscitation 2005. Section 4: advanced life support. Resuscitation 2005, 67(Suppl 1):S39-S86.

12. Handley AJ, Koster R, Monsieurs K, Perkins GD, Davies S, Bossaert L: European Resuscitation Council guidelines for resuscitation 2005. Section 2. Adult basic life support and use of automated external defibrillators. Resuscitation 2005, 67(Suppl 1):S7-S23.

13. Whitfield RH, Newcombe RG, Woollard M: Reliability of the Cardiff Test of basic life support and automated external defibrillation version 3.1. Resuscitation 2003, 59:291-314.

14. Nolan JP, Deakin CD, Soar J, Bottiger BW, Smith G: European Resuscitation Council guidelines for resuscitation 2005. Section 4. Adult advanced life support. Resuscitation 2005, 67(Suppl 1):S39-S86.

15. Deakin CD, Nolan JP, Soar J, Sunde K, Koster RW, Smith GB, Perkins GD: European Resuscitation Council Guidelines for Resuscitation 2010 Section 4. Adult advanced life support. Resuscitation 2010, 81:1305-1352.

16. Edelson DP, Abella BS, Kramer-Johansen J, Wik L, Myklebust H, Barry AM, Merchant RM, Hoek TL, Steen PA, Becker LB: Effects of compression depth and pre-shock pauses predict defibrillation failure during cardiac arrest. Resuscitation 2006, 71:137-145.

17. Berg RA, Sanders AB, Kern KB, Hilwig RW, Heidenreich JW, Porter ME, Ewy GA: Adverse hemodynamic effects of interrupting chest compressions for rescue breathing during cardiopulmonary resuscitation for ventricular fibrillation cardiac arrest. Circulation 2001, 104:2465-2470.

18. Kern KB, Hilwig RW, Berg RA, Sanders AB, Ewy GA: Importance of continuous chest compressions during cardiopulmonary resuscitation: improved outcome during a simulated single lay-rescuer scenario. Circulation 2002, 105:645-649.

19. Olasveengen TM, Vik E, Kuzovlev A, Sunde K: Effect of implementation of new resuscitation guidelines on quality of cardiopulmonary resuscitation and survival. Resuscitation 2009, 80:407-411.
20. Sayre MR, Cantrell SA, White LJ, Hiestand BC, Keseg DP, Koser S: Impact of the 2005 American Heart Association cardiopulmonary resuscitation and emergency cardiovascular care guidelines on out-of-hospital cardiac arrest survival. Prehosp Emerg Care 2009, 13:469-477.

21. Krarup NH, Terkelsen CJ, Johnsen SP, Clemmensen P, Olivecrona GK, Hansen TM, Trautner S, Lassen JF: Quality of cardiopulmonary resuscitation in out-of-hospital cardiac arrest is hampered by interruptions in chest compressions-a nationwide prospective feasibility study. Resuscitation 2011, 82:263-269.

22. Edelson DP, Litzinger B, Arora V, Walsh D, Kim S, Lauderdale DS, Vanden Hoek TL, Becker LB, Abella BS: Improving in-hospital cardiac arrest process and outcomes with performance debriefing. Arch Intern Med 2008, 168:1063-1069.

23. Kramer-Johansen J, Myklebust H, Wik L, Fellows B, Svensson L, Sorebo H, Steen PA: Quality of out-of-hospital cardiopulmonary resuscitation with real time automated feedback: a prospective interventional study. Resuscitation 2006, 71:283-292.

24. Olasveengen TM, Tomlinson AE, Wik L, Sunde K, Steen PA, Myklebust $H$, Kramer-Johansen J: A failed attempt to improve quality of out-of-hospital CPR through performance evaluation. Prehosp Emerg Care 2007, 11:427-433.

25. Liberman M, Lavoie A, Mulder D, Sampalis J: Cardiopulmonary resuscitation: errors made by pre-hospital emergency medical personnel. Resuscitation 1999, 42:47-55.

26. Sunde K, Wik L, Steen PA: Quality of mechanical, manual standard and active compression-decompression CPR on the arrest site and during transport in a manikin model. Resuscitation 1997, 34:235-242.

27. Aufderheide TP, Sigurdsson G, Pirrallo RG, Yannopoulos D, McKnite S, von Briesen C, Sparks CW, Conrad CJ, Provo TA, Lurie KG: Hyperventilation-induced hypotension during cardiopulmonary resuscitation. Circulation 2004, 109:1960-1965.

28. Isbye DL, Rasmussen LS, Lippert FK, Rudolph SF, Ringsted CV: Laypersons may learn basic life support in 24 min using a personal resuscitation manikin. Resuscitation 2006, 69:435-442.

29. Nielsen AM, Henriksen MJ, Isbye DL, Lippert FK, Rasmussen LS: Acquisition and retention of basic life support skills in an untrained population using a personal resuscitation manikin and video self-instruction (VSI). Resuscitation 2010, 81:1156-1160.

30. Nielsen AM, Isbye DL, Lippert F, Rasmussen LS: Distributing personal resuscitation manikins in an untrained population: how well are basic life support skills acquired? Emergency medicine journal, in press.

31. Nielsen AM, Isbye DL, Lippert FK: Have the 2005 guidelines for resuscitation been implemented? Ugeskr Laeger 2008, 170:3843-3847.

doi:10.1186/1757-7241-20-34

Cite this article as: Nielsen et al:: Basic life support and automated external defibrillator skills among ambulance personnel: a manikin study performed in a rural low-volume ambulance setting. Scandinavian Journal of Trauma, Resuscitation and Emergency Medicine 2012 20:34.

\section{Submit your next manuscript to BioMed Central and take full advantage of:}

- Convenient online submission

- Thorough peer review

- No space constraints or color figure charges

- Immediate publication on acceptance

- Inclusion in PubMed, CAS, Scopus and Google Scholar

- Research which is freely available for redistribution 